\title{
THE EFFECTS OF FISCAL AND MONETARY DISCIPLINE ON BUDGETARY OUTCOMES
}

\author{
BILIN NEYAPTI and SECIL OZGUR*
}

\begin{abstract}
This article extends the model of Von Hagen and Harden that analyzed the impact of fiscal discipline on budgetary outcomes. We modify the model by adding monetary discipline to interact with fiscal discipline in order to analyze the effects of both on budgetary outcomes. The model predicts that while both inflation and budget deficits are negatively associated with fiscal discipline, they may be positively associated with monetary discipline, proxied by central bank independence. This result obtains due to optimizing agents internalizing the burden of spending: inflation. Although not conclusive due to data limitations, empirical findings also support these predictions. (JEL D73, E58, H61, H72)
\end{abstract}

\section{INTRODUCTION}

During the 1980s and prior to the establishment of the European Central Bank (ECB), macroeconomic performances have shown considerable variation in Europe (see Appendix I), as did the institutional structures. The convergence criteria with respect to the level of inflation, budget deficits, government debt, and the interest rates ${ }^{1}$ that emerged during the process of establishing the European Monetary Union, however, heightened the importance of fiscal and monetary discipline in all the member countries. Achieving convergence is considered to help obtain the potential benefits of integration while reducing or eliminating the possible transfers from well-performing members toward those who lack fiscal stability. In this regard, the establishment of the ECB can be considered as a mechanism for establishing a common institutional structure to achieve monetary discipline in the member countries.

*We would like to thank to Erdem Basci and the participants of the seminar at Bilkent University, The Center for Economic Design, and to anonymous referees for their valuable comments. We are responsible for all the remaining errors. S.O. was a Masters Student at Bilkent University when she contributed to the article. This article was first received by the journal in May, 2004.

Neyapti: Associate Professor, Department of Economics, Bilkent University, 06533 Bilkent, Ankara, Turkey. E-mail: neyapti@bilkent.edu.tr

Ozgur: Former Masters Student, Department of Econom-

ics, Bilkent University, 06533 Bilkent, Ankara, Turkey.

1. These criteria are no more than the lowest three inflation rates in the Union plus $1.5 \% ; 3 \%$ of gross domestic product (GDP); $60 \%$ of GDP; and no more than the yield of the three best performers plus $2 \%$, respectively.
This article investigates, both theoretically and empirically, the effects on budgetary outcomes of fiscal and monetary discipline induced by the corresponding institutional rules. Though our reference point for the theoretical framework and the empirical application refers to European countries, however, implications of the study can be generalized to others.

Von Hagen (1992) proposes a list of criteria to measure fiscal discipline and demonstrates a significant empirical linkage between fiscal discipline and the budgetary outcomes in 12 Organization for Economic Cooperation and Development (OECD) economies. Furthermore, Von Hagen and Harden (1995, H\&H herein) provide a theoretical framework to analyze the effect of fiscal discipline on the level of spending bias, which arises due to private utility gains from spending, in the European Community countries. H\&H's model suggests a positive relation between the spending bias

\section{ABBREVIATIONS}

CBI: Central Bank Independence ECB: European Central Bank FMD: Financial Market Development GDP: Gross Domestic Product

H\&H: Von Hagen and Harden (1995)

IFD: Indices of Fiscal Discipline

LVESX: Legal CBI-restricted, Cukierman et al. (2002)

LVAW: Legal CBI, Cukierman et al. (1992)

OECD: Organization for Economic Cooperation and Development

SM: Spending Minister 
and the relative strength of spending ministers' (SMs') individual incentives against the collective interest of the government. Fiscal illusion, defined as the overestimation of the marginal benefit of a public activity, arises from the fact that while funding for a public spending usually comes from the general public, it benefits only a specific group within the public. Hence, while the constituency of each SM receives the entire fund allocated to a specific activity, they become only partially accountable for the burden generated on the aggregate budget.

$\mathrm{H} \& \mathrm{H}$ also provide empirical support for the limiting effect on fiscal illusion of the institutional rules that govern budgetary processes. Among a comprehensive set of the formal and informal rules of behavior and interaction that govern budgetary processes, $\mathrm{H} \& \mathrm{H}$ particularly consider four characteristics, namely, the structure of budget negotiations within the government, the rules of the parliamentary process, the flexibility of budget execution, and the informativeness of the budget draft. To make an empirical assessment of the effectiveness of such rules in reducing fiscal illusion, Von Hagen (1992) constructs an index that characterizes institutional provisions in the national budget processes for 12 OECD countries. ${ }^{2}$

This article argues that in addition to the institutional rules that exert fiscal discipline, rules that exert monetary discipline have potentially important effects on budgetary outcomes. To that end, we extend the model of $\mathrm{H} \& \mathrm{H}$ by incorporating a measure of monetary discipline in order to investigate the effect of both institutional rules on budgetary outcomes. We argue that central bank independence (CBI), as a mechanism of credible commitment to price stability, proxies monetary discipline and may also contribute to fiscal discipline by constraining the spending decision of the government.

Rogoff (1985) and Cukierman (1992), among others, provide theoretical discussion on the positive relationship between CBI and price stability. Empirical studies also support this positive association (see, e.g., Alesina and Summers, 1993; Cukierman, Webb, and Neyapti, 1992; Eijffinger and De Haan, 1996; Grilli, Masciandro, and Tabellini, 1991). Neyapti (2003) provides evi-

2. Since we use this index in the empirical part of this analysis, Appendix II provides details of construction of the index. dence that inflationary effects of budget deficits are also lower in case of $\mathrm{CBI} .^{3}$

In contrast with this literature, however, both Beetsma and Uhlig (1998) and Cukierman and Lippi (1999) build models that suggest another possible channel leading to a negative linkage between CBI and price stability. The principal feature of these models is that a low degree of CBI may perform the function of a fiscal disciplining device such that economic agents will have to internalize the potential costs of inflation. It is therefore possible for a central bank to be "too independent." Based on a model of a strategic interaction between central bank and workers' unions, Cukierman and Lippi (1999) demonstrate that CBI may be positively associated with inflation in the case of a high degree of inflation aversion by unions. This result is obtained because the lower the degree of $\mathrm{CBI}$, the greater the extent of internalization of the inflation cost by the labor unions, and thus the lower the demands for real wage increases. Beetsma and Uhlig (1998), on the other hand, demonstrate the negative effect of an independent ECB on fiscal discipline. They argue that in the case of the $\mathrm{ECB},{ }^{4}$ the union governments may tend to generate higher levels of debt than before since they do not fully internalize the resulting burden, which is potentially at a higher rate of future inflation. Average debt burden can thus rise as an unintended consequence of an independent ECB.

To investigate the relative effects of fiscal and monetary discipline on fiscal outcomes, we keep the basic features of the $\mathrm{H} \& \mathrm{H}$ model in that we assess fiscal discipline through budgetary processes distinguished on the basis of the strategic dominance of the government over the SMs. In addition, however, we modify H\&H's model by incorporating a budget constraint and by assuming that CBI, as an institutional device for monetary discipline, is negatively related with the monetization of the budget. ${ }^{5}$

3. CBI may play a role in the relationship between budget deficits and inflation both via lower monetary accommodation and-especially-via lower expectations of future monetary accommodation of deficits.

4. ECB is generally considered to be an independent institution. Indeed, based on the set of criteria proposed in Cukierman, Webb, and Neyapti (1992), its legal independence exceeds that of individual member countries' central banks, including that of Germany.

5. An independent central bank may also represent a constituency that has an interest in reducing the inflation burden of spending (see, e.g., Goodman, 1991; Posen, 1994). 
The current model yields explicit solutions for the level of budget deficits and inflation that are both in negative relation with the degree of centralization of the budget decision, or with the degree of fiscal discipline. An interesting implication of the model, however, is that spending bias is positively related with CBI. This apparent anomaly arises since the burden of extra spending, inflation, is internalized by both the government and the SMs. A significant contribution of this article is that, notwithstanding the Sargent and Wallace (1981) results of the positive relationship between inflation and the lack of monetary discipline, it shows that high degree of CBI, as an institutional manifestation of monetary discipline, may in fact lead to moral hazard among the agents who decide on the budget. Moreover, the impact of monetary discipline on the economy is not linear and depends on the fiscal rules.

As an empirical test of the model's predictions, we investigate the relative roles of fiscal and monetary discipline in the same 12 OECD countries during the 1980s. Even though constrained with the small sample problem, our empirical investigation supports the model's main propositions. The relevance of the findings in this article, however, is likely to extend to other countries.

The rest of the article is organized as follows. Section II presents the model. Section III provides a comparative analysis of the outcomes under different budgetary processes. Some empirical evidence is provided in Section IV. Section V concludes.

\section{THE MODEL}

$\mathrm{H} \& \mathrm{H}$ investigate the linkage between fiscal performance and fiscal discipline, based on Von Hagen (1992) who evaluates fiscal discipline based on various features of the budgetary processes. ${ }^{6}$ In a game-theoretic approach, they distinguish between different budgetary processes as follows: (i) the government's collective optimization, (ii) individual SMs' optimization, and (iii) Nash bargaining between SMs over their budgetary allocations. Of the latter two budgetary processes, the first one results from

6. The authors distinguish between essentially two budgetary procedures. In the first approach, called a "procedure-oriented" approach, the budget process vests ministers without portfolio with special strategic powers. The second approach to budgeting, the "target-oriented" approach, involves the government's collective negotiation of a set of binding numerical rules for the budget. the aggregation of each of the SMs' bid, and the second one results from the SMs' negotiation over their budgetary allocations.

The current model extends the model of $\mathrm{H} \& \mathrm{H}$ to incorporate the possible effects of monetary discipline on budgetary decisions. To this end, the current model modifies H\&H's model first by introducing a budget constraint for the government's optimization problem. Second, it explicitly defines the burden of additional spending in terms of deviation from an inflation target, rather than in terms of the total spending by the SMs, as we argue that social excess burden is the part of that spending that is inflationary. The model assumes that the part of the government's financing requirement that is monetized is negatively related with the degree of monetary discipline. We hypothesize that the latter can be proxied by the degree of CBI; while various factors may affect the degree of monetization from one period to the other, degree of CBI can be considered as a stable indicator of the degree of monetary discipline. In the following, we present the model incorporating these features into all three types of the budgeting decisions as postulated by $\mathrm{H} \& \mathrm{H}$. The optimization problems pertain to a government and to $n-$ SMs. Each SM chooses a spending level $x_{i}$ that may deviate from an exogenously given target level of public activity, $X_{i}^{*}$, where $i=1, \ldots, n$.

\section{A. Government's Collective Optimization ( $G$ )}

The government's collective interest is to minimize both the deviations of all spending levels from their respective targets and the social excess burden generated by the aggregate of such deviations. The government's joint utility function thus involves deviations of both the spending by the SMs and inflation from their respective targets. Hence, the government maximizes the following joint utility function $(U)$ with respect to the $X_{i}^{\prime}$ 's:

$$
U=-\sum_{i=1}^{n} \frac{a}{2}\left(X_{i}-X_{i}^{*}\right)^{2}-\frac{b}{2}\left(\Pi-\Pi^{*}\right)^{2},
$$

subject to the budget constraint:

$$
D=\sum_{i=1}^{n} X_{i}-\sum_{i=1}^{n} T_{i}+r B_{t-1} \leq d M+d B
$$

where $a$ and $b$ in Equation (1) represent the government's loss for each unit of the quadratic 
disutility received for the deviations of spending and inflation ( $\Pi)$ from their respective targets. In Equation (2), $D$ is the government's financing requirement, or deficits; $T_{i}$ is the tax revenue obtained from the constituency of $\mathrm{SM} i ; r B_{-1}$ is the interest payments for the outstanding debt $B_{-1} ; d M$ is the part of deficits that is financed through money issue, where $M$ is the money stock; and $d B$ is the part that is financed through new bond issue.

We assume that the part of deficits that is financed through money issue is inversely related with the degree of $\mathrm{CBI}{ }^{7}$

$$
d M=\gamma D,
$$

where $\gamma$ is the degree of-the lack-CBI. ${ }^{8}$ Hence, the lower the $\gamma$, the higher the CBI. In addition, we assume that all monetary expansion is inflationary and, thus, $d M=$ $\Pi M$ holds in a steady-state, where $\Pi M$ is the inflation tax. ${ }^{9}$ Hence, the relationship between inflation and deficits becomes:

$$
\Pi=\gamma D / M \text {. }
$$

We further assume that since the degree of $\mathrm{CBI}$ is known with certainty, the degree of monetization, and thus the inflation burden, of spending is also known both by the government and by the ministers prior to their spending decision. As optimizing agents, they thus adjust their spending, given their degree of aversion to inflation. The collective optimization (by the government) with respect to the level of spending thus yields the following expression:

$$
\left(X_{i}-X_{i}^{*}\right)=-\frac{b \gamma}{a M}\left(\Pi-\Pi^{*}\right) \text { for each } i .
$$

This solution implies that if $\gamma$ is zero, that is, if the central bank is totally independent, all the SMs' spending are on target and inflation is zero (due to Equation 4). ${ }^{10}$ Otherwise, there is a negative relationship between the deviations of spending and inflation from their respective targets. This can be interpreted as follows: the

7. Berument (1998) shows for 18 OECD countries that $\mathrm{CBI}$ is inversely related with seignorage revenues.

8. Equation (2), the budget constraint, becomes an equality in case one writes: $d B=(1-\gamma) D$.

9. By totally differentiating $m=M / P$ and assuming that there is no change in real money balances, we obtain $d M / M=d P / P$ which then yields $d M=\Pi M$.

10 . Given an inflation target $\Pi^{*}$, the spending targets $X_{i}^{*}$ could be chosen such that both targets are met; that is, $\Pi=\Pi^{*}$ and $X_{i}^{*}=X_{i}$ emerges as a solution for all $i$. government may allow spending to exceed its target level if the overall burden of spending, the inflation rate, is below its target. The trade-off is such that, for given spending and inflation targets, total deviation of all spending from its targets can be higher the lower the deviation of inflation from its target. The higher is the degree of CBI, the smaller is this trade-off.

\section{B. SMS' Individual Optimization (SM)}

Similar to the government, each SM gets a quadratic disutility from the deviations of both its level of spending and inflation from their respective targets. However, each SM also benefits, by a factor " $c$ ", from the level of his/her spending. Hence, the SM optimizes the following problem with respect to the level of its spending:

$$
V_{i}=c X_{i}-\frac{d}{2}\left(X_{i}-X_{i}^{*}\right)^{2}-\frac{e_{i}}{2}\left(\Pi-\Pi^{*}\right)^{2} .
$$

The solution becomes:

$$
\left(X_{i}-X_{i}^{*}\right)=\frac{c}{d}-\frac{e_{i} \gamma}{M d}\left(\Pi-\Pi^{*}\right)
$$

Assuming that both the government and the SMs give equal weights to the deviations of spending and inflation from their respective targets, that is, if $a=d$ and $(b / n)=e_{i}$, then the spending bias arising from the collection of each SM's optimum choice vis-a-vis the government's solution becomes: $c / a-[\gamma(n-1) / n d](\Pi$ $\left.-\Pi^{*}\right)$. For $\gamma=0$, the case of full CBI, the bias, $c / a$, is positive. The sign of the bias is positive so long as $\gamma$ (the inverse of the degree of CBI) follows the condition $\gamma\left(\Pi-\Pi^{*}\right)<c$ (assuming that $[(n-1) / n]$ is close to one, or $n$ is large).

\section{Nash Bargaining among the SMs (NB)}

Alternatively, total spending may be decided upon by negotiations among SMs over their budgetary allocations, the total of which is then allocated equally.

This is tantamount to the Nash bargaining solution of $\mathrm{H} \& \mathrm{H}$, which obtains from the optimization of $\Sigma V_{i}$ with respect to $X_{i}$, assuming that $e_{i}$ 's are the same for all $i=1, \ldots, n$. Equation (8) shows the result of this optimization:

$$
\left(X_{i}-X_{i}^{*}\right)=\frac{c}{d}-\frac{e \gamma n}{M d}\left(\Pi-\Pi^{*}\right) .
$$

Hence, for $\gamma=0$, the Nash bargaining solution yields the same spending bias as in the case of the aggregation of individual optimal 
spending decisions by the SMs. For $\gamma \neq 0$, that is when central bank is not completely independent; however, this solution leads to a lower spending bias (due to the addition of term $n$ to the second part of the expression) than in the case of individual optimization by the SMs.

\section{A COMPARATIVE ANALYSIS OF THE OUTCOMES OF DIFFERENT BUDGETARY PROCESSES}

For analytical convenience, we assume that inflation tax is the only form of tax and thus $T_{i}=0$ for all $i$ in Equation (2). If, without loss of generality, we can assume that the inflation target is zero, $b$ becomes the cost of inflation. If $b$ is equal to $M$, the money stock, the burden can be interpreted as the amount of inflation tax, $M \Pi .^{11}$ Analogously, the parameter that identifies the cost of inflation burden for each $\mathrm{SM}, e_{i}$, now defines the SM's share of the inflation tax. More specifically, we assume that the constituencies of SM hold equal amounts of money balances and thus suffer from the inflation tax by $e_{i}=(M / n)$. We further assume that $a=d .{ }^{12}$ These assumptions help simplify the expressions in Equations (5), (7), and (8) for comparative purposes.

Table 1 summarizes the outcomes in terms of the deviation of deficits from its target, $(D-$ $\left.D^{*}\right)$, when Equations (5), (7), and (8) are aggregated for $n$ SMs. Propositions 1-4 summarize the findings based on the above solutions.

\section{PROPOSITION 1. Under the foregoing} assumptions, deviations of both deficits and inflation from their respective targets can be ranked with respect to the three budgeting procedures as: $G \leq N B \leq S M$.

Hence, the government's collective solution yields lower budget deficits, and thus lower inflation rates, than the SMs' either individual optimization or Nash bargaining solutions. This shows that the extent of centralization of budgetary processes has a restrictive role on the spending bias. This is consistent with the main result of $\mathrm{H} \& \mathrm{H}$ in that when dominated by individual interests of SMs, budgetary processes yield a higher burden than otherwise.

11. Here, the implicit assumption is that $b$ might not be a constant degree of inflation aversion, but it might change as the amount of money stock changes.

12. The latter two assumptions indicate that the weights given to the deviations of spending and inflation from their respective targets are the same for both the government and SMs.
TABLE 1

Deviation of Budget Deficits from Target and Fiscal Discipline

\begin{tabular}{ll}
\hline $\begin{array}{l}\text { Government's collective } \\
\text { optimization (G) }\end{array}$ & $\left(D-D^{*}\right)=-\frac{n \gamma}{a}\left(\Pi-\Pi^{*}\right)$ \\
$\begin{array}{l}\text { SMs' individual } \\
\text { optimization (SM) }\end{array}$ & $\left(D-D^{*}\right)=\frac{c n}{a}-\frac{\gamma}{a}\left(\Pi-\Pi^{*}\right)$ \\
$\begin{array}{l}\text { SMs' Nash } \\
\text { bargaining (NB) }\end{array}$ & $\left(D-D^{*}\right)=\frac{c n}{a}-\frac{\gamma n}{a}\left(\Pi-\Pi^{*}\right)$ \\
\hline
\end{tabular}

Notes: Assumptions made to obtain comparable results are $\Sigma e_{i}=b=M ; e_{i}=M / n ;$ and $a=d$.

After substituting Equation (4) in the expressions reported in Table 1 and solving for $D$ in terms of the model parameters, $M$, and the target values, we obtain ambiguous results for the partial derivative of $D$ with respect to $\gamma$ (or CBI). Under the following conditions, obtained for each of the above models (denoted by G, SM, and NB), however, both deficits and inflation $(D$ and $\Pi)$ have a negative relationship with $\mathrm{CBI}$ :

$$
\mathrm{G}: \gamma<\left(\frac{\Pi^{*} M a}{n \Pi^{*} \gamma+2 a D^{*}}\right)
$$

$$
\begin{aligned}
& \mathrm{SM}: \gamma<\left(\frac{\Pi^{*} M a}{\Pi^{*} \gamma^{2}+2 a D^{*}+2 c n}\right), \\
& \mathrm{NB}: \gamma<\left(\frac{\Pi^{*} M a}{n \Pi^{*} \gamma+2 a D^{*}+2 c n}\right) .
\end{aligned}
$$

Otherwise, $D$ (and $\Pi$ ) is positively related with CBI (or negatively related with $\gamma$ ). Hence, depending on the parameter values, these conditions imply some "critical" levels of CBI for each of the problem type such that below that level the disciplining feature of CBI prevails, and above it, it fails to achieve its intended goals.

The inspection of the above conditions implies that the minimum degree of CBI (the maximum $\gamma$ ) needed to obtain the negative relationship between $\mathrm{CBI}$ and deficit (or inflation) is the largest for the case of SMs' Nash bargaining. If the condition that $\gamma \Pi^{*}(n-\gamma)>$ $2 c n$ holds, then it is also larger for SM's individual optimization than for the government's collective optimization. ${ }^{13}$ This outcome provides a new perspective for the expected impact of the monetary institutions on the economy in view of different fiscal rules.

13. Note that $\left(n \gamma \Pi^{*}\right)$ is greater than $\left(\gamma^{2} \Pi^{*}\right)$. 
PROPOSITION 2. The range of values of $C B I$ that leads to a positive association between $C B I$ and deficits (or inflation) is wider for $N B$ than for $S M$ and $G$. If $\left[\gamma \Pi^{*}(n-\gamma)>2 c n\right]$, then it is also wider for $S M$ than for $G$. Interpreting the above conditions conversely, the degree of $C B I$ below which a positive relationship between deficits (or inflation) and CBI obtains is smaller in the case of $G$ than both NB and SM.

The intuition behind this seemingly perverse result is as follows. The SMs, especially in case of Nash bargaining, internalize the burden of inflation because the constituency of each SM holds some amount of money balances $\left(e_{i}\right)$ whose value deteriorates with inflation. Hence, the lower the degree of independence of the central bank, the more the SMs become averse to spending that leads to inflation. That is, the lack of monetary discipline, measured in terms of the lack of CBI, increases fiscal discipline on the part of the SMs who internalize the burden of inflation. ${ }^{14}$

The above conditions also indicate that the impact of CBI not only depends on the existing fiscal rules and other parameter values but also is nonlinear, a proposition that is subject to further investigation and empirical testing.

PROPOSITION 3. Keeping everything else constant, an increase in the number of SMS (n) increases deficit ${ }^{15}$ in the case of either individual optimization or Nash bargaining by the SMs. ${ }^{16}$ This effect, however, is negative in the case of the government's collective optimization.

A possible explanation for this asymmetry is that, unlike SMs, the government takes into account the full cost of the increase in spending. Thus, as $n$ increases, the expectation that both the level of total spending and inflation would increase may lead the government to cut back on total spending and thus deficits.

PROPOSITION 4. Keeping everything else constant, the higher the utility received from individual SM's spending (c), the higher are

14. Though one may argue that inflation also reduces the debt burden and may thus be desirable, it should be noted that the debt burden is not the responsibility of individual SMs, but of the central government, and thus does not neutralize the aforementioned anti-inflationary incentives for the SMs.

15. As well as the spending bias that arises from SMs' individual optimization solution, as observed from the sum of the expression in Equation (7).

16. The partial derivatives of deficits with respect to the number of SMs for SM and NB are as follow: $c M a l$ $\left(a^{2} M+\gamma^{2}\right)$ and $c M a /\left(a^{2} M+\gamma^{2} n\right)$, respectively. the spending biases and budget deficits. This positive relationship is stronger in the case of individual optimization by the SMs than in the case of their Nash bargaining.

To summarize, the main finding of the above analysis is that the interaction between the fiscal and monetary institutions matters for budgetary outcomes. More specifically, in view of the above model one can argue that high degrees of CBI may actually hamper fiscal discipline, causing some form of moral hazard. To express it differently, there may be some level of CBI below which fiscal discipline increases to overcome the implied losses from lack of monetary discipline. ${ }^{17}$ In addition, the model implies that the more decentralized the budgetary procedure and the larger the number of decentralized units, the higher is the spending bias.

\section{EMPIRICAL EVIDENCE}

To test for the findings of the foregoing model, we use yearly inflation rates and the ratio of budget deficits to GDP in averages over the period from 1981 to 1990 (source: International Financial Statistics of the International Monetary Fund). Data cover the 12 OECD countries studied in Von Hagen (1992), for which the indices of fiscal discipline (IFD) is available. ${ }^{18}$ Though the data are limited to claim sound evidence in favor or disfavor of the model predictions, we nevertheless provide the results of this preliminary analysis.

To measure fiscal discipline, we employ the broad structural index (SI1) constructed in Von Hagen (1992). ${ }^{19}$ As measures of the degree of CBI, we use the aggregate-weighted index of legal independence developed by Cukierman, Webb, and Neyapti (1992) and a subset defined in Cukierman, Miller, and Neyapti (2002). We call these latter indices with their original abbreviations LVAW and

17. Analysis of these optimal levels for specific countries would require calibration of the results based on the assumptions of model parameters, namely the target levels, number of SMs, as well as the weights in the objective functions.

18. While there is the potential problem of varying degrees of quasi-fiscal deficits across countries' fiscal accounts, the need to use a standard measurement of budget deficits leads us to employ the data as reported in the International Monetary Fund statistics.

19. Narrow definitions of the structural index, SI3, yield virtually the same results and are therefore not reported here. 
TABLE 2

Average Inflation and Budget Deficits Grouped by Degrees of Fiscal Discipline and CBI: 1981-1990

IFD (SI1)

\begin{tabular}{|c|c|c|c|c|c|}
\hline \multirow[b]{2}{*}{ CBI Indices } & & \multicolumn{2}{|c|}{$\begin{array}{l}\text { Average Deficits } \\
\text { to GDP Ratio }\end{array}$} & \multicolumn{2}{|c|}{ Average Inflation Rates } \\
\hline & & $\operatorname{High}^{\mathbf{a}}$ & Low $^{\text {b }}$ & High & Low \\
\hline \multirow[t]{2}{*}{ LVAW } & High & $2.7^{\mathrm{c}}(3)^{\mathrm{d}}$ & 9.7 (3) & $3.72(3)$ & $14.73(3)$ \\
\hline & Low & $2.2(2)$ & $6.0(4)$ & $6.48(2)$ & $7.03(4)$ \\
\hline \multirow[t]{2}{*}{ LVESX } & High & $1.8(3)$ & $9.9(2)$ & $4.98(3)$ & $13.45(2)$ \\
\hline & Low & $3.5(2)$ & $6.6(5)$ & $4.59(2)$ & $9.09(5)$ \\
\hline
\end{tabular}

\footnotetext{
${ }^{\text {a }}$ High: referring to those values of indices that are greater than the mean of the whole sample.

b Low: referring to those values of indices that are smaller than the mean of the whole sample.

${ }^{\mathrm{c}}$ The average of 1981-1990.

${ }^{\mathrm{d}}$ The size of the sample.
}

LVESX, respectively. ${ }^{20}$ Appendix II reports the list of criteria for the construction of both the IFD and legal CBI.

Our empirical analysis is cross-sectional since neither IFD nor CBI changes in the sample countries over the period analyzed here. Data are therefore rather limited to perform a multiple regression analysis in order to investigate the respective roles of CBI and IFD on both deficits and inflation. Thus, we simply look at the averages of inflation rates and budget deficits corresponding to the high and low (with respect to a mean value) values of both IFD and the CBI index. Table 2 summarizes the findings.

According to Table 2, both inflation rates and budget deficits are substantially lower for the high (relative to the observed average) values of the IFD than for their low values. This finding is consistent with that of both $\mathrm{H} \& \mathrm{H}$ and Proposition 1 above. When we view the sample across the high and low classification of CBI, however, an interesting picture arises; both budget deficits and inflation take their highest average values in the cases of low IFD, but high CBI (see italicized figures in Table 2). This observation is in support of Proposition 2 in suggesting the possibility of positive association of these variables with $\mathrm{CBI}$.

20. Following Eijffinger and Schaling (1993) and Eijffinger and van Keulen (1995), we employ a subset of the legal CBI index to account for those characteristics that are suggested to have greater relevance than some other aspects of CBI. LVESX is one such narrow index that consists only of the criteria on the allocation of authority for monetary policy, conflict resolution, objectives of the central bank, and the limitations on lending to the government.
Appendix III investigates the possible interactions between fiscal and monetary discipline by looking at the correspondences between high and low values of IFD and CBI. Those tables reveal that the CBI indices are substantially higher for higher values of the IFD, and vice versa. Hence, the results call for care in designing an empirical analysis of the relative roles of IFD and CBI on fiscal performance.

\section{SUMMARY AND CONCLUSIONS}

This article incorporates the central bank behavior into the model of $\mathrm{H} \& \mathrm{H}$ in order to investigate jointly the effects of fiscal and monetary discipline on budgetary outcomes. While we argue that monetary discipline can be proxied by the degree of CBI, fiscal discipline is investigated via different budgetary procedures laid out in $\mathrm{H} \& \mathrm{H}$.

As in $\mathrm{H} \& \mathrm{H}$, the current model predicts that fiscal illusion is limited by fiscal discipline. However, it also suggests the possibility of a positive relationship between fiscal illusion and the degree of CBI. The rationale for this being that the lower the degree of $\mathrm{CBI}$, the more the burden (in the form of inflation tax) is incurred by the constituencies of the SMs, who then choose to spend less than otherwise. As the number of SMs increase, however, both budget deficits and inflation increase in the case of the optimizing SMs since the resulting burden on the constituency of each SM gets smaller. In case of Nash bargaining among SMs, however, this effect is smaller than in the case of individual optimization. 
The current model indicates that high degrees of CBI, which symbolizes the institutionalization of monetary discipline, may lead to moral hazard among the spending agents of the government. Thus, it is possible to observe higher levels of deficits and inflation associated with institutions established with the purpose of achieving monetary discipline. Using the IFD developed by $\mathrm{H} \& \mathrm{H}$ and the indices of CBI developed by Cukierman, Webb, and Neyapti (1992), we provide a preliminary empirical investigation of the predictions of this model. Although not entirely conclusive, the evidence supports model predictions. Data also exhibit substantial interaction between IFD and CBI.

One needs to consider, however, that there may be various other factors besides the degree of CBI that affect fiscal discipline, or the nature of the relationship between $\mathrm{CBI}$ and fiscal discipline, and thus budgetary outcomes. As Neyapti (2003) points out, financial market development (FMD) enables noninflationary financing of budget deficits. Like CBI, FMD may thus lead to lower fiscal discipline. In other words, under high FMD, one may observe that a given degree of CBI may be coupled with even higher budget deficits than that predicted with this model, indicating that FMD may add to the moral hazard effect of high CBI.

In the context of this model, the varying degrees of independence of the central banks of the European Community members during the 1980s (see Cukierman, Webb, and Neyapti, 1992) may help predict the deviations among the European Community members with regards to their future fiscal performance. In addition, the budgetary developments upon the establishment of the ECB, whose constitution implies a high degree of independence, offer a natural experiment; the deviation of French and German budgets from the Maastricht criteria is an example of the moral hazard problem predicted in the current model.

The implications of the current analysis are, of course, not limited with the countries studied here. This article can be extended to a wider set of countries as comparable data on fiscal discipline become available. ${ }^{21}$

21. Alesina et al. (1996) and Gleich (2003) have studied different set of countries with respect to different budgetary discipline indices. Reconciling their differences and thus putting these different data sets together, however, is the subject of a separate study of more empirical emphasis.
APPENDIX I. MACROECONOMIC AND INSTITUTIONAL INDICATORS IN THE EUROPEAN UNION, 1980S

TABLE A1.A

Macroeconomic Indicators in the European Union, 1980-1990

\begin{tabular}{lrrr}
\hline Country & $\begin{array}{l}\text { Deficit/ } \\
\text { GDP }\end{array}$ & $\begin{array}{l}\text { Inflation } \\
\text { Rate }\end{array}$ & $\begin{array}{l}\text { Gross Public } \\
\text { Debt/GDP }\end{array}$ \\
\hline Belgium & 9.68 & 4.71 & 116.76 \\
Denmark & 1.46 & 6.30 & 66.13 \\
France & 2.55 & 6.70 & 32.31 \\
Germany & 1.48 & 2.63 & 41.99 \\
Greece & 10.68 & 18.90 & 61.82 \\
Ireland & 9.18 & 8.35 & 102.51 \\
Italy & 12.23 & 10.08 & 83.72 \\
Luxembourg & -3.52 & 4.54 & 12.35 \\
Netherlands & 5.20 & 2.46 & 68.50 \\
Portugal & 9.21 & 17.75 & 63.60 \\
Spain & 5.41 & 9.66 & 40.82 \\
United Kingdom & 1.78 & 6.27 & 54.26 \\
Mean & 5.45 & 8.20 & 62.06 \\
Standard deviation & 4.80 & 5.31 & 29.28 \\
Coefficient of variation & 0.88 & 0.65 & 0.47 \\
\hline
\end{tabular}

Notes: Deficit and inflation figures are in averages for 1980-1989; debt figures are in averages for 1980-1990. Source: OECD.

TABLE A1.B

Indices of Fiscal and Monetary Discipline

\begin{tabular}{lcccc}
\hline Country & SI1 $^{\mathbf{a}}$ & SI3 $^{\mathbf{a}}$ & LVAW $^{\mathbf{b}}$ & LVESX $^{\mathbf{b}}$ \\
\hline Belgium & 0.34 & 0.18 & 0.20 & 0.08 \\
Denmark & 0.60 & 0.68 & 0.53 & 0.87 \\
France & 0.86 & 0.94 & 0.27 & 0.51 \\
Germany & 0.65 & 0.44 & 0.73 & 0.87 \\
Greece & 0.32 & 0.03 & 0.59 & 0.53 \\
Ireland & 0.34 & 0.31 & 0.48 & 0.80 \\
Italy & 0.25 & 0.38 & 0.29 & 0.20 \\
Luxembourg & 0.23 & 0.19 & 0.37 & 0.42 \\
Netherlands & 0.62 & 0.74 & 0.45 & 0.37 \\
Portugal & 0.40 & 0.30 & 0.44 & 0.37 \\
Spain & 0.31 & 0.28 & 0.27 & 0.25 \\
United Kingdom & 0.73 & 0.86 & 0.30 & 0.04 \\
Mean & 0.47 & 0.44 & 0.41 & 0.44 \\
Standard deviation & 0.21 & 0.29 & 0.16 & 0.29 \\
Coefficient of variation & 0.45 & 0.66 & 0.38 & 0.65 \\
\hline
\end{tabular}

${ }^{\text {a }}$ SI 1 and SI3 are IFD derived from the broad and narrow indices defined by $\mathrm{H} \& \mathrm{H}$.

${ }^{b}$ LVAW and LVESX are the broad and narrow indices of CBI defined in Cukierman, Webb, and Neyapti (1992) and Cukierman, Miller, and Neyapti (2002), respectively. 


\section{APPENDIX II. CRITERIA TO EVALUATE FISCAL AND MONETARY DISCIPLINE}

TABLE A2.A

List of Criteria for Constructing the IFD, Von Hagen (1992)

1. Structure of negotiations within government:

a. General constraint: the rule for designing overall budget

b. Agenda setting for budget negotiations

c. Scope of budget norms in the setting of agenda

d. Structure of negotiations

2. Structure of parliamentary process:
a. Amendments
b. Required to be offsetting
c. Can cause fall of government
d. All expenditures passed in one vote
e. Global vote on total budget size.

3. Informativeness of the budget draft:

a. Special funds included

b. Budget submitted in one document

c. Assessment of budget transparency by respondents

d. Link to national accounts

e. Government loans to nongovernment entities included in budget draft

4. Flexibility of budget execution:

a. Minister of Finance block expenditures

b. Spending ministries subject to cash limits

c. Disbursement approval required from Minister of Finance or controller

d. Transfers of expenditures between chapters

e. Changes in budget law during execution

f. Carryover of unused funds to next year

Notes: Each of the subitems under the four main headings is enumerated between 0 and 4 for each country. SI 1 is the sum resulting from the numbers from 1 to 4 including all subitems. Von Hagen also enumerates SI 2 as the sum of items 1,2 , and 4 , and SI3 as the sum of items 1 and 2 .
TABLE A2.B

List of Criteria for Constructing the Index of CBI-Cukierman, Webb, and

Neyapti (1992)

1. $\mathrm{CEO}$

a. Term of office

b. Who appoints CEO?

c. Dismissals

d. May CEO hold other offices in government?

2. Policy formulation

a. Who formulates monetary policy?

b. Who has final word in resolution of conflict?

c. Role in government's budgetary process

3. Objectives

4. Limitations on lending to the government

a. Advances

b. Securitized lending

c. Terms of lending

d. Potential borrowers from the bank

e. Limits on central bank lending

f. Maturity of loans

g. Interest rates on loans

h. Central bank prohibited from buying or selling government securities in the primary market?

Notes: The construction details of the indices of CBI, LVAW, and LVESX are available in Cukierman, Webb, and Neyapti (1992) and Cukierman, Miller, and Neyapti (2002), respectively. CEO, chief executive officer.

\section{APPENDIX III. INTERACTION BETWEEN} IFD AND CBI

TABLE A3.A

Average Values of CBI by Groups of IFD

\begin{tabular}{lccc}
\hline & \multicolumn{2}{c}{ IFD } \\
\cline { 2 - 4 } Indices of CBI & SI1 & SI3 & Low \\
LVAW & High & $0.377(7)$ & $\begin{array}{c}\text { Total Sample } \\
\text { Average }\end{array}$ \\
\hline LVESX & $0.456(5)$ & $0.247(7)$ & $\mathbf{0 . 4 1 0}(12)$ \\
& $0.532(5)$ & SI3 & $\mathbf{0 . 4 4 3}(12)$ \\
\cline { 2 - 4 } & SI3 & Low & \\
LVAW & High & $0.377(7)$ & $\mathbf{0 . 4 1 0}(12)$ \\
\cline { 2 - 4 } & $0.456(5)$ & $0.379(7)$ & $\mathbf{0 . 4 4 3}(12)$ \\
\hline
\end{tabular}


TABLE A3.B

Average Values of IFD by Groups of CBI

\begin{tabular}{|c|c|c|c|}
\hline \multirow[b]{3}{*}{ IFD } & \multicolumn{2}{|c|}{ Indices of CBI } & \multirow[b]{3}{*}{ Total Sample Average } \\
\hline & \multicolumn{2}{|c|}{ LVAW } & \\
\hline & High & Low & \\
\hline \multirow[t]{3}{*}{ SI1 } & $0.692(5)$ & $0.313(7)$ & $0.471(12)$ \\
\hline & \multicolumn{2}{|c|}{ LVESX } & \\
\hline & High & Low & \\
\hline SI1 & $0.532(5)$ & $0.379(7)$ & $0.471(12)$ \\
\hline
\end{tabular}

\section{REFERENCES}

Alesina, A., R. Hausmann, R. Hommes, and E. Stein. "Budget Institutions and Fiscal Performance in Latin America." National Bureau of Economic Research Working Paper No. 5586, 1996.

Alesina, A., and L. H. Summers. "Central Bank Independence and Macroeconomic Performance: Some Comparative Evidence." Journal of Money, Credit, and Banking, 25, 1993, 151-62.

Beetsma, R., and H. Uhlig. "An Analysis of the Stability and Growth Pact." Cahiers de Recherche, Forschungsberichte, Research Papers, July 1998.

Berument, H. "Central Bank Independence and Financing Government Spending." Journal of Macroeconomics, 20, 1998, 133-51.

Cukierman, A. Central Bank Strategy, Credibility and Independence: Theory and Evidence. Cambridge, Mass.: MIT Press, 1992.

Cukierman, A., and F. Lippi. "Central Bank Independence, Centralization of Wage Bargaining, Inflation and Unemployment-Theory and Some Evidence." European Economic Review, 43, 1999, 1395-434.

Cukierman, A., G. Miller, and B. Neyapti. "Central Bank Independence, Liberalization and Inflation in Transition Economies." Journal of Monetary Economics, 49, 2002, 237-64.
Cukierman, A., S. B. Webb, and B. Neyapti. "Measuring the Independence of Central Banks and its Effect on Policy Outcomes.' World Bank Economic Review, 6, 1992, 353-98.

Eijffinger, S., and J. De Haan. "The Political Economy of Central Bank Independence.” Special Papers in International Economics, No. 19, International Finance Section, Department of Economics, Princeton University, 1996.

Eijffinger, S., and E. Schaling. "Central Bank Independence in Twelve Industrial Countries." Banca Nazionale del Lavoro Quarterly Review, 184, 1993, 64-8.

Eijffinger, S., and M. van Keulen. "Central Bank Independence in Another Eleven Countries." Banca Nazionale del Lavoro Quarterly Review, 192, 1995, 39-83.

Gleich, H. "Budget Institutions and Fiscal Performance in Central and Eastern European Countries." ECB Working Paper No. 215, 2003.

Goodman, J. B. "The Politics of Central Bank Independence." Comparative Politics, April 1991, 329-49.

Grilli, V., D. Masciandro, and G. Tabellini. "Economic and Monetary Institutions and Public Financial Policies in the Industrial Countries." Economic Policy, 13, 1991, 340-92.

Neyapti, B. "Budget Deficits and Inflation: An Investigation of the Roles of Central Bank Independence and Financial Market Development." Contemporary Economic Policy, 21, 2003, 458-75.

Posen, A. "Why Central Bank Independence Does not Cause Low Inflation," in R. O'Brien (editor). Finance and International Economy, Oxford: Oxford University Press, 1994.

Rogoff, K. "The Optimal Degree of Commitment to an Intermediate Monetary Target." Quarterly Journal of Economics, 100, 1985, 1169-90.

Sargent, T., and N. Wallace. "Some Unpleasant Monetary Arithmetics." Quarterly Review, Federal Reserve Bank of Minneapolis, 9, 1981, 15-31.

Von Hagen, J. "Budgeting Procedures and Fiscal Performance in the EC." Economic Papers-96, European Commissions, Brussels, 1992.

Von Hagen, J., and I. J. Harden. "Budget Processes and Commitment to Fiscal Discipline." European Economic Review, 39, 1995, 771-9. 